\title{
Exploring sales data during a healthy corner store intervention in Toronto: the Food Retail Environments Shaping Health (FRESH) project
}

\section{Leia M. Minaker, PhD (1); Meghan Lynch, PhD (2); Brian E. Cook, PhD (3); Catherine L. Mah, MD, PhD (2,4)}

This article has been peer reviewed.

\begin{abstract}
Introduction: Population health interventions in the retail food environment, such as corner store interventions, aim to influence the kind of cues consumers receive so that they are more often directed toward healthier options. Research that addresses financial aspects of retail interventions, particularly using outcome measures such as store sales that are central to retail decision making, is limited. This study explored store sales over time and across product categories during a healthy corner store intervention in a lowincome neighbourhood in Toronto, Ontario.
\end{abstract}

Methods: Sales data (from August 2014 to April 2015) were aggregated by product category and by day. We used Microsoft Excel pivot tables to summarize and visually present sales data. We conducted $t$-tests to examine differences in product category sales by "peak" versus "nonpeak" sales days.

Results: Overall store sales peaked on the days at the end of each month, aligned with the issuing of social assistance payments. Revenue spikes on peak sales days were driven predominantly by transit pass sales. On peak sales days, mean sales of nonnutritious snacks and cigarettes were marginally higher than on other days of the month. Finally, creative strategies to increase sales of fresh vegetables and fruits seemed to substantially increase revenue from these product categories.

Conclusion: Store sales data is an important store-level metric of food environment intervention success. Furthermore, data-driven decision making by retailers can be important for tailoring interventions. Future interventions and research should consider partnerships and additional success metrics for retail food environment interventions in diverse Canadian contexts.

Keywords: retail food environment, population health intervention, sales data, convenience stores

\section{Introduction}

Retail food environment interventions in stores (e.g. grocery store and corner store interventions) are increasingly recognized as important public health interventions to improve the nutritional quality of food purchases. ${ }^{1-4}$ Such interventions aim to support healthier dietary behaviours by improving access to and availability of affordable, nutritious food options in the community and consumer nutrition environments. ${ }^{5,6}$ Food stores are especially important sites for healthy eating interventions, since over 70 cents of every household food dollar is spent in stores (as opposed to restaurants). ${ }^{\text {? }}$

Food sales data have been proposed as valuable, objective, cost-efficient and unobtrusive
Highlights

- Public health practitioners interested in retail food environment interventions can use sales data to inform comprehensive evaluations.

- Sales data can be used to tailor healthy corner store interventions to the local context (for example, special promotions on peak sales days).

- Using sales data is important for research and also for store owners, who can use sales data metrics to inform their own business practices.

measures of diet-related behaviour that place no burden on individual participants. ${ }^{8}$ Store sales data (e.g. directly collected checkout scanner data, commercially available data sets and grocery receipts) have been used to monitor the effectiveness of interventions in a variety of types of retail food stores, ${ }^{9-12}$ including a number of recent small-store studies. ${ }^{13-17}$ Together, these studies suggest that sales data can actually be used in the design of retail food interventions. For example, Foster and colleagues ${ }^{9}$ found that low-cost strategies focussed on improving product availability and placement enhanced sales of some foods and beverage categories (milk, water, frozen meals) but not others (regular soda, diet soda, cereal).

A recent systematic review of the effectiveness of supermarket interventions aimed at improving the healthiness of consumer purchases found that of 49 relevant studies identified, none reported on the economic or financial effects of the

\section{Author references:}

1. School of Planning, University of Waterloo, Waterloo, Ontario, Canada

2. Dalla Lana School of Public Health, University of Toronto, Toronto, Ontario, Canada

3. Toronto Food Strategy, Toronto Public Health, Toronto, Ontario, Canada

4. Faculty of Health, Dalhousie University, Halifax, Nova Scotia, Canada

Correspondence: Leia M. Minaker, School of Planning, University of Waterloo, 200 University Ave., W., Waterloo, ON N2L3G1; Tel: 519-888-4567 ext. 35615; Email: Iminaker@uwaterloo.ca 
intervention on the retailer. ${ }^{4}$ A 2012 narrative review of grocery marketing strategies aimed at improving diet found that only 5 of 125 reviewed studies used sales data to evaluate impacts of diverse strategies. ${ }^{3}$ Another 2012 review that examined impacts of retail interventions in small food stores found the majority of studies (11 of 16 evaluations) did not analyze sales data. ${ }^{2}$ Only a few studies have used sales data to assess retail performance of the store as the primary outcome of interest. ${ }^{18}$ There are many reasons why previous research has not used sales data, including the potentially sensitive nature of the data, and its poor quality due to human error or technological barriers. However, the lack of published sales outcomes remains a significant gap in this body of research, because even if well-designed retail food environment interventions can successfully improve dietary behaviours in the population, the population-level impact will not be sustained unless the intervention's effects align with retailers' economic goals.

Given the importance of economic data to decision making in retail settings, treating sales data as an important metric in retail food environment intervention evaluation is crucial for both implementation and intervention sustainability. ${ }^{4}$ Within the retail sector, smaller stores have reduced capacity to engage in data-driven decision making. Evaluating sales may increase the potential to promote healthy retailing interventions among a diversity of food retailers, ${ }^{19}$ especially given store owner concerns about potential revenue loss..$^{20,21}$ Indeed, lack of sales data from previous studies may act as a barrier to other stores adopting healthy food interventions. In addition to retailers, this type of information is also important for legislators who are considering how to craft policies to support healthy food environments in Canadian jurisdictions. ${ }^{22}$

The objective of the current study was to characterize store sales over time over the course of a healthy food retailing intervention in a low-income, urban neighbourhood. We examined food and beverage sales, as well as sales in several nonfood product categories. We present nonfood product category sales in this article to provide context in terms of potential risks and opportunities small retailers face when they implement a healthy food retail intervention.

\section{Methods}

The Food Retail Environments Shaping Health (FRESH) study was funded by the Public Health Agency of Canada, led by Toronto Food Strategy (an initiative of Toronto Public Health) and collected data from August 2014 to April 2015. The FRESH study used mixed methods to assess individual-level dietary and food security impacts of a pilot healthy corner store intervention and a mobile good food market intervention (a retrofitted city bus that distributed and sold fresh vegetables and fruits to neighbourhoods with low grocery store access) in two low-income neighbourhoods in Toronto, Ontario. This article reports on sales data from the corner store that participated in the healthy corner store intervention. Unfortunately, sales data from the mobile good food market were of poor quality and therefore unreportable.

\section{Setting}

The neighbourhood in which the intervention corner store was situated was in Scarborough East - Ward 43 in Toronto, Ontario, a ward in which $42 \%$ of residents live in apartment buildings with more than five stories, $52 \%$ of residents were born outside of Canada, $57 \%$ of residents speak English as a first language and average annual household income is roughly $\$ 20000$ less than the Toronto average. ${ }^{23,24}$ The intervention corner store was situated in the heart of Scarborough East, on the main floor of an apartment tower complex. The site was identified by Toronto Food Strategy in partnership with East Scarborough Storefront, a community organization aiming to support people and build community in Scarborough East. We approached storeowners to participate, and they became active participants in all intervention decisions and in sales data collection. Unpublished data from the broader FRESH study (which included surveys with $\mathrm{n}=199$ residents who were primary food shoppers and lived in the intervention apartment tower) showed that among residents of the apartment tower complex in which the store was located, $83.3 \%$ were born outside Canada, $69 \%$ had at least one child and $78 \%$ had annual household incomes below \$30 000 .

\section{Intervention}

The transformation of the convenience store pilot site was an iterative process encompassing (1) business fundamentals, including food procurement, infrastructure and sales analytics; (2) customer service and engagement; and (3) various merchandising strategies. Key goals of the intervention were to improve supplier relationships and merchandising to increase availability and prominence of nutritious foods and beverages. In this intervention, "nutritious foods and beverages" were considered those that aligned with Canada's Food Guide recommendations. In collaboration with public health dietitians from Toronto Public Health and with the store owners, we identified specific nutritious foods and beverages to be sold (e.g. fresh whole fruits and vegetables, water, popcorn, low-sugar granola bars, snack packs of vegetables). We introduced and promoted nutritious foods over the course of the intervention. Nutritious items were priced competitively with comparable products at the nearby discount supermarket (approximately $1 \mathrm{~km}$ away). The initial recruitment of the corner store took place in December 2013; the infrastructure changes to support the sale of fresh produce, such as purchasing and installing new refrigeration units and changes to existing shelving, happened between June 2014 and February 2015; and fresh produce began to be offered for sale in June 2014.

To increase the store's year-round fresh fruit and vegetable supply, Toronto Food Strategy connected store owners with a Toronto-based fruit and vegetable distributor. Toronto Food Strategy helped store owners open an account, and trained them in the ordering process. The store owners also procured fruits and vegetables from a nearby local Asian supermarket. Members of the research team visited the store between one and three times per week throughout the intervention to provide ongoing support, including training on sales data collection through the pointof-sale (POS) system (described below).

Of relevance to this study was the fact that the apartment tower's residential landlord company had its own ongoing free snack program available every school day to all children living in the apartment tower. Every week, the landlords purchased fresh produce for the snack program from a nearby warehouse-style club store to distribute to school children. In November 2014, the store owners successfully negotiated with the landlords to 
begin supplying the fresh produce for the snack program at the same price.

Several challenges to consistent implementation emerged throughout the intervention, including making improvements to general business operations, engaging store owners in considering data quality, building capacity in data-driven retail decision making, creating merchandising strategies, establishing links with the community, and negotiating complex relationships between the store owners and regular customers. These challenges are consistent with those observed in other healthy corner store intervention contexts. ${ }^{20}$

\section{Measures}

We collected sales data through a POS system. The POS system was installed in January 2014, and tracked the date and time of sale, UPC code, researcher-programmed product category (e.g. sweetened beverage, bottled water, candy, fruit, vegetable, lottery tickets, cigarettes, etc.), quantity purchased and item price. A company that specializes in digital marketing inside convenience stores supported the project by providing the POS equipment, installation, maintenance and training at no cost. The company tracks advertising effectiveness in the corner stores with which they work, and agreed to advertise only nutritious foods and beverages throughout the project. The research team was able to request updated sales data on a regular basis from the POS provider throughout the project. Although the POS system was installed in January 2014, it took several months for reliable data to become available, and to build practical capacity in data management and use of the POS system on the part of the store owners. Data presented here therefore have been restricted to the consistently higher quality data obtained from August 2014 to April 2015, the last month for which data were available. In addition, we restricted our analyses to revenue (overall store sales generated by retail items) rather than profits (revenue less expenses), since comprehensive data on expenses were not collected.

\section{Analysis}

We aggregated sales data by product category and by day to examine store sales over time. We used pivot tables to organize and summarize data in Microsoft Excel. We also created visual representations of sales data using graphing features in Microsoft Excel.

First, we summarized total store sales by day and plotted the data on a graph over time to visually inspect the consistency of store sales over time. Preliminary findings suggested that store sales appeared to spike on certain days of the month, which we refer to as "peak" sales days throughout the remainder of this paper. Further investigation revealed that peak sales days consistently occurred the day after social assistance payments were issued. We examined daily sales of products in different categories by "peak" versus "nonpeak" sales days, and created two-tailed $t$-tests with unequal variances to examine whether product category sales differed significantly by "peak" and "nonpeak" days; $p<.05$ was considered statistically significant.

Second, we graphically displayed monthly revenue generated by different product categories over time. The sale of fruits and vegetables (as one of the main components of the intervention) was also examined visually over time. Given the store owners' negotiation with the landlords to supply fresh produce for the free snack program in November 2014 (described earlier), we present fruit and vegetable sales data with and without snack program sales to provide an accurate representation of fruit and vegetable sales to regular customers.

\section{Results}

Figure 1 shows the total daily sales (excluding lottery sales) of the pilot intervention corner store between August 2014 and April 2015. Figure 2 shows mean daily sales of different product categories sold during the peak sales days and the nonpeak sales days. During both peak and nonpeak sales days, transit passes and tickets, lottery tickets and cigarettes accounted for the highest overall sales. On peak sales days, mean daily sales of cigarettes were marginally significantly higher than nonpeak days ( $\$ 175.73$ for peak sales days compared to $\$ 130.09$ for nonpeak sales days, $p=.084$ ). Mean sales of nonnutritious snacks and beverages were also marginally higher on peak days (\$85.04 for snacks and $\$ 74.34$ for beverages per day) than on nonpeak days ( $\$ 61.67$ for snacks $[p=.078]$ and $\$ 56.39$ for beverages $[p=.145]$ per day). Lottery sales $(p=.023)$ and public transit ticket sales $(p<.0001)$ were significantly higher on peak than on nonpeak days.

Figure 3 shows monthly revenue generated from four product categories over time: fresh produce, snacks (including candy, chocolate, potato chips and other salty snacks and meat snacks), sweetened beverages and cigarettes. Throughout the course of the intervention, revenue from cigarettes was high. Revenue from fresh produce went from \$165 in August 2014 to over $\$ 1000$ per month for the months of January to April 2015. Revenue generated from fresh produce overtook revenue of sweetened beverages and snacks in January 2015, but fell slightly below sweetened beverage and snack revenue in March and April 2015.

Finally, monthly gross revenue from fruits and vegetables by overall revenue and by revenue generated from individual consumer sales (i.e. excluding fruit and vegetable sales to the landlord) are presented in Figure 4. On average, the store generated approximately $\$ 935$ in revenue from fresh produce per month over the six months that landlords purchased fruit through the intervention store.

\section{Discussion}

This exploratory study described the characteristics of sales data from a corner store participating in a government-led healthy corner store intervention in a low-income apartment tower neighbourhood in Toronto, Ontario. The data presented are among the first sales data to be examined in a study of retail food environment interventions in a Canadian context, ${ }^{10,19}$ and the first sales data to be examined in a healthy corner store intervention in Canada. This study does not make claims about consumer-level impacts but more simply aims to characterize store revenue generated over the course of an intervention, along with potential interpretations of sales trends in relation to the urban small-store retailing context.

This study contributes three key findings relevant for research and public health practice in Canada. First, intervention store sales peaked at predictable time intervals (the day after social assistance cheques were issued). Furthermore, mean sales of some product categories varied significantly between these peak sales days and the other days of the month. Second, intervention store sales captured 
FIGURE 1

Store total daily sales, excluding lottery sales, during a healthy corner store intervention in Toronto, Ontario, August 2014 to April 2015

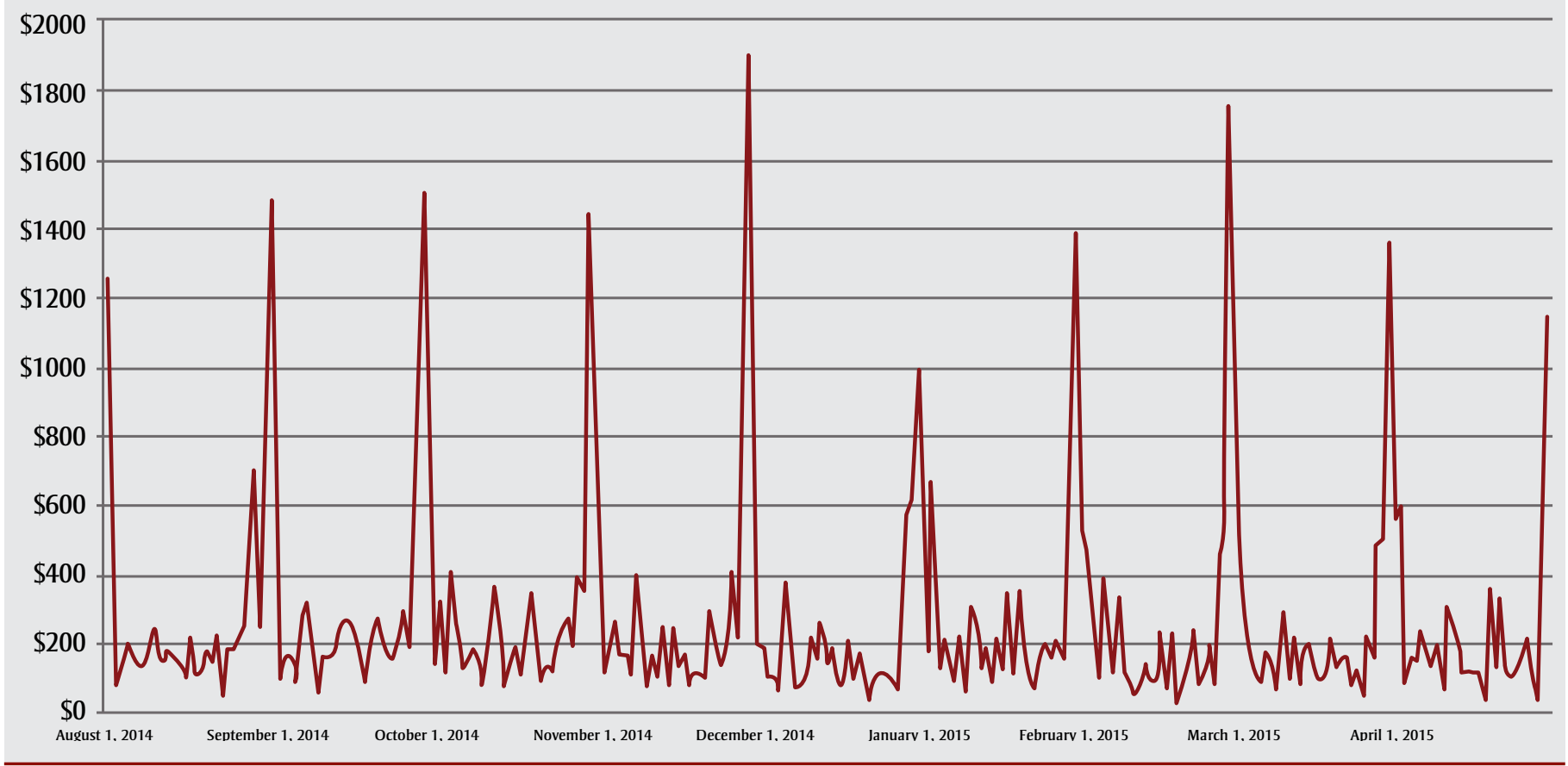

longitudinal change in product mix over time. Third, reporting, visualizing and assisting the store owners with interpreting sales promoted the concept of datadriven decision making, and seemed to catalyze store owners' willingness to incorporate new products such as fresh fruits and vegetables.
Each of these findings is addressed in more detail below.

First, this is the first study, to our knowledge, to report how corner store sales peaked the day after social assistance cheques were issued in a low-income neighbourhood. This finding has implications for corner store interventions in similar neighbourhood contexts. Specifically, strategies to shift consumer purchasing behaviours on peak sales days (when store traffic may be higher), including instore interventions, could be explored. The proportion of overall store sales from lottery tickets, transit tickets, cigarettes and

FIGURE 2

Average daily sales for different product categories for peak (highest sales days) and nonpeak days during a healthy corner store intervention in Toronto, Ontario, August 2014 to April 2015

Transit passes and tickets

Lottery

Cigarettes

Non-nutritious snacks

Non-nutritious beverages

Bottled water

Vegetables and fruit

Household items

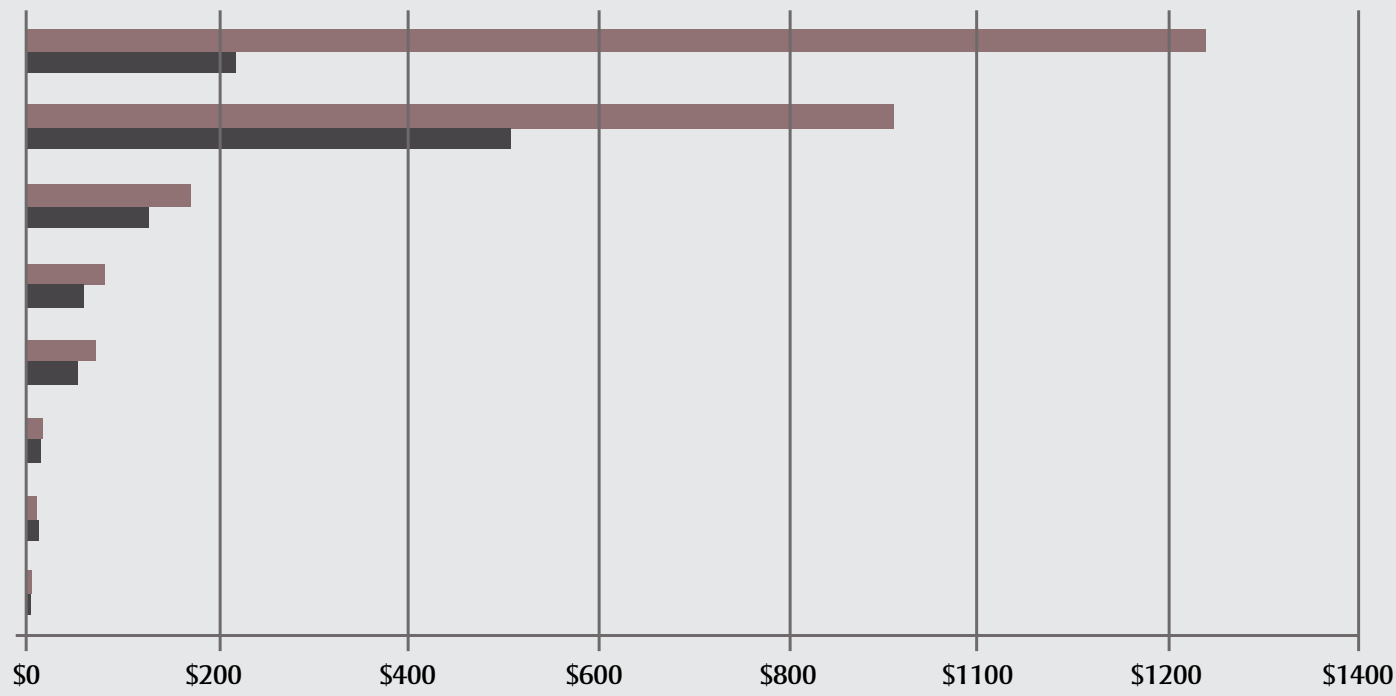

Peak average

Nonpeak average 
FIGURE 3

Monthly gross revenue from four product categories during a healthy corner store intervention in Toronto, Ontario, August 2014 to April 2015

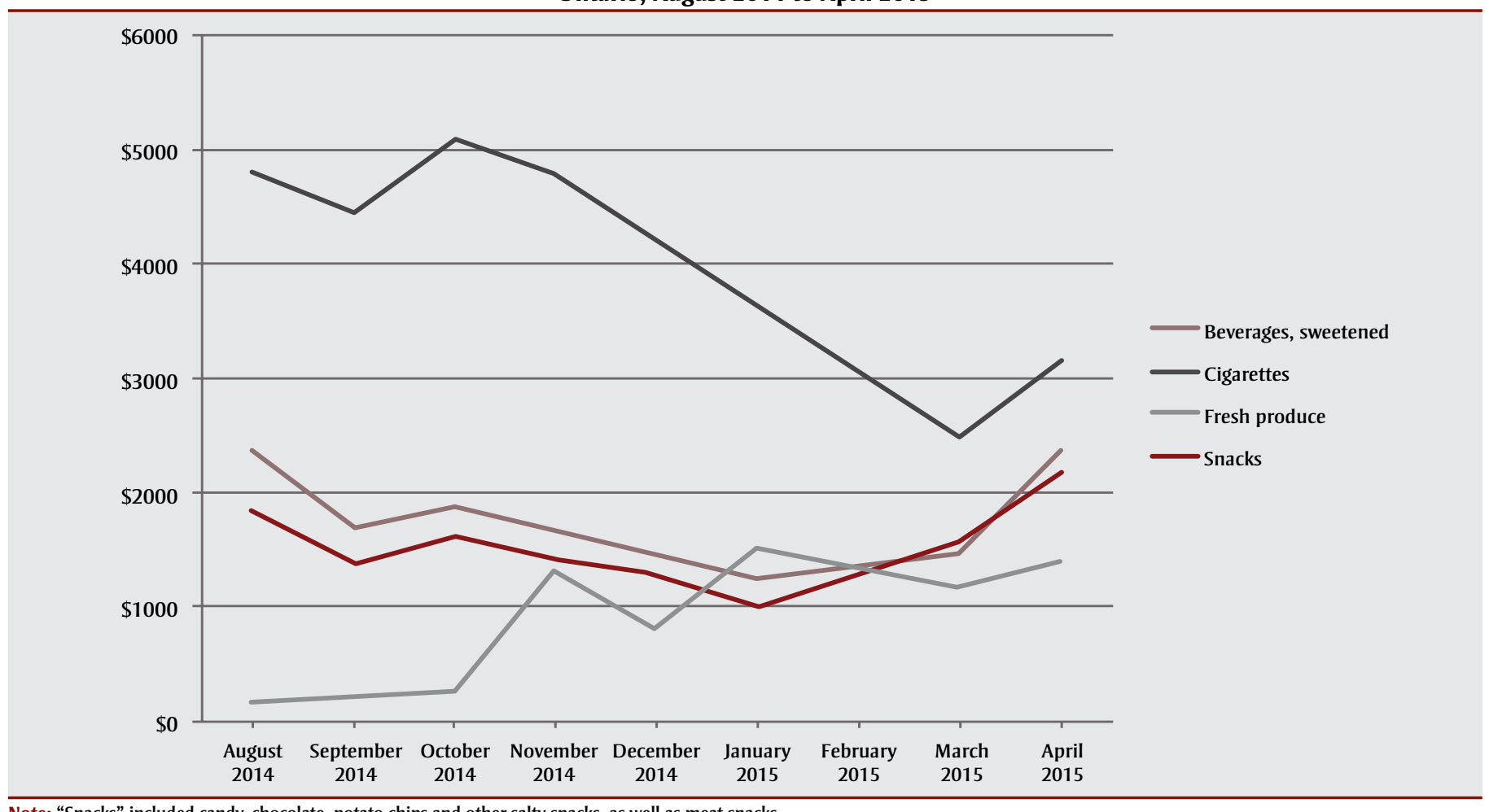

Note: "Snacks" included candy, chocolate, potato chips and other salty snacks, as well as meat snacks.

nonnutritious snacks and beverages was significantly or marginally higher on peak days compared to nonpeak days, but there were no differences in sales of fruits and vegetables, bottled water or household items. These findings also highlight the importance of distinguishing between sales data analysis at an ecological (store or community) versus an individual level. The proportion of overall store sales from different product categories cannot be attributed to individual- or household-level characteristics. However, previous research with low-income families in Toronto has demonstrated the resourcefulness of those living under serious economic constraints manifested in household food insecurity, ${ }^{25,26}$ and the wide array of factors contributing

FIGURE 4

Monthly gross revenue from fresh produce generated over the course of a healthy corner store intervention with and without fruit sales to landlords, Toronto, Ontario, August 2014 to April 2015

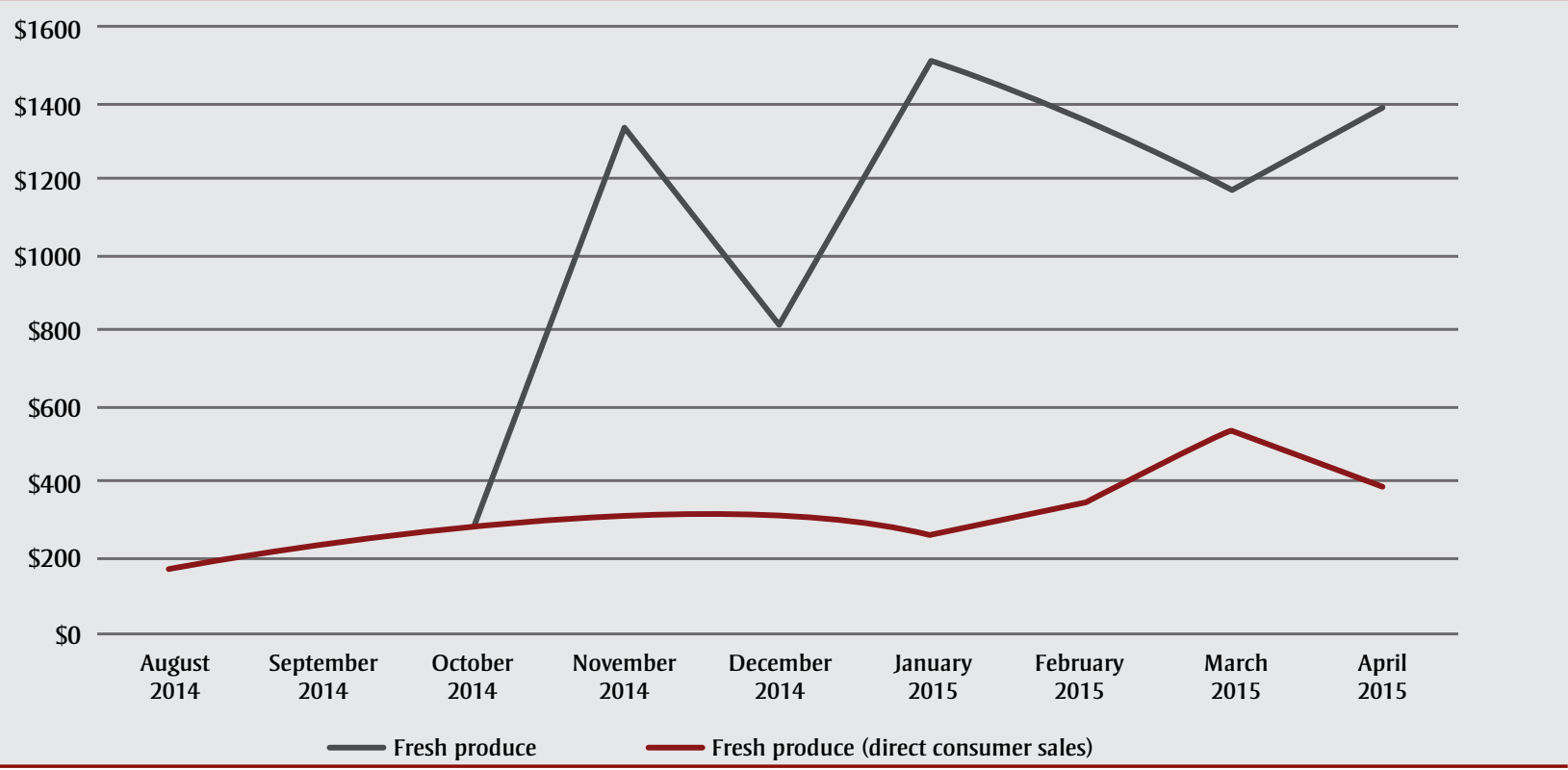


to decision making with household budgets. For example, among low-income families, while price is a key factor in purchasing decisions, and social assistance payments appear to structure monthly food purchases, economizing may depend on preference and health considerations, as well as perishability, durability and other value attributes associated with food items. ${ }^{25}$ Future research should further explore reasons for differences in food purchasing over the course of a month, given more and less severe economic constraints at different times of the month.

Second, in terms of product mix, the use of sales data meant that we could explore longitudinal variation in sales of different product categories over time. In retail stores, the majority of sales typically come from a limited number of product lines, even with a diverse inventory. The intervention corner store primarily focussed on typical urban convenience store product lines, including tobacco, lottery, subway/ bus tokens, sweetened beverages and unhealthy snacks. Over time, however, the introduction and promotion of various fruits and vegetables through the healthy corner store intervention saw these items gain a larger share of store revenue. Changing to a more health-promoting product mix in corner stores requires creativity and entrepreneurialism, as we have discussed elsewhere. ${ }^{27}$ Although this study focussed on store sales, one substantial contribution to revenue- $68 \%$ of total fruit and vegetable revenue-consisted of sales to the apartment tower landlord company, as described above. Irrespective of this unique opportunity, however, fruit and vegetable sales to individual customers also showed a steady increase over time, which is important to note for future healthy corner store programs for which bulk sales opportunities do not exist. That said, from a practical standpoint, creative approaches to financial sustainability for retail food environment interventions seem to be foundational for success. ${ }^{20,28}$ Moreover, to the extent that small-store interventions become inclusive of other public health objectives (for example, reducing tobacco consumption), creative strategies to build consumer traffic and diversify revenue streams are required.

Third, reporting, visualizing and assisting the store owners with interpreting sales data promoted the concept of data-driven decision making, and seemed to catalyze store owners' willingness to incorporate new products such as fresh fruits and vegetables. Using sales data, the owners were able to objectively assess the revenue generated by different product categories, and to track which types of merchandizing most substantially increased sales of different nutritious foods, and when they did so. Moreover, summarizing sales data prior to the implementation of an intervention could provide an idea of the potential risks and benefits retailers face when intervening in certain product categories, which may help to guide intervention implementation.

\section{Strengths and limitations}

Strengths of this study include the use of objective sales data rather than store owner perceptions about store sales, which are commonly reflected in the literature. $^{2,29}$ In addition, it contributes to a new and growing body of literature that seeks to explore additional metrics of retail food environment intervention outcomes that have traditionally not been included in similar research (for a variety of reasons), particularly sales data.

Our study also has several limitations. First, we only examined sales data from one store. While this is a common approach in the literature, ${ }^{2,30}$ our findings may not be generalizable to other Canadian settings or contexts.

Second, we were unable to report on sales data from the very beginning of the intervention, given difficulties in the consistent use of the POS system for the first several months. Conversations with the corner store owners revealed that while the technical use of the POS system was one issue, owners' business practices (e.g. not recording every item sold) also contributed to lack of consistent data collected during the first few months. A related limitation is that the POS system was not equipped to capture data on where purchased items were placed around the store (e.g. in high-traffic areas such as endcaps, or near the cash register), nor was it equipped to capture sales or promoted items. Future research could combine data from POS systems and planograms (diagrams that indicate the placement of retail products on shelves to maximize sales) to examine how sales of different nutritious products vary by placement.
Third, this study only examined revenue generated by different product categories, rather than profit (revenue less the cost of selling the item, including capital inputs, and taxation). Our sales data did not consider the number of items sold, but rather the overall sales in dollars. Therefore, we were unable to detect variation in the number of fruit and vegetable servings sold. Nevertheless, the store owners purposely set fruit and vegetable prices to be competitive with the nearest discount supermarket, so we anticipated that any slight price changes over time during our study would not have significantly impacted consumer behaviour (e.g. cause them to avoid the corner store). This is a limitation that should be addressed by future research. For example, although tobacco sales made up a substantial proportion of store revenue throughout the intervention, conversations with the store owners revealed their desire to stop selling tobacco because of the security risk it poses (in terms of theft) and because of diminishing profit margins. On the other hand, while fresh fruits and vegetables accounted for a smaller proportion of revenue, profit margins are typically high, ${ }^{30}$ which provides a financial incentive for owners to continue to stock and sell these items.

Fourth, in addition to infrastructure investments (e.g. fridges and appropriate shelving), selling fresh food in a corner store requires substantial commitment on behalf of store owners and staff. Store staff must become skilled in food handling and safety training, developing relationships with suppliers, negotiating favourable prices and terms, displaying fresh produce, understanding customer needs and desires and finding revenue streams to reduce spoilage costs (for example, making sandwich wraps that use unsold fresh vegetables or installing a smoothie station for unsold fruit). Moreover, corner store owners often perceive that fresh produce will not sell, which may be based on previous experience. ${ }^{20,30}$ Still, small-store interventions can significantly increase revenue generated from fresh produce sales, and therefore remain an important population health intervention for future research. $^{2,30}$

\section{Conclusion}

Retail food environment interventions are gaining traction as a public health intervention with the potential for multiple 
positive societal outcomes if enacted widely, including improved diet at a population level. Much research must still be done to further describe metrics for the success of these types of interventions for different audiences, recognizing the competing priorities of diverse stakeholders. Sales data are critical in evaluating the economic feasibility of stores adapting their business models to support healthy diets in Canada, but often such data are proprietary and collecting them for public health research requires partnerships between industry and public sector researchers. Public-private partnerships are a current and contentious issue in Canada's public health community, and tools for guiding public health actors in partnership development for food-related partnership are available. $^{31}$ Future interventions and research would do well to carefully consider partnerships and success metrics for retail food environment interventions in diverse Canadian contexts.

\section{Acknowledgements}

We would like to gratefully acknowledge the reviewers who provided excellent suggestions on previous versions of this manuscript. LMM also acknowledges funding from the Canadian Cancer Society in the form of a Career Development Award in Cancer Prevention (\#704744). This research was funded by the Public Health Agency of Canada.

\section{Conflicts of interest}

The authors declare no conflicts of interest.

\section{Authors' contributions}

LMM conceived of the study and co-wrote the manuscript with ML. BEC conducted data analyses. LMM, BEC, and CLM devised and implemented the overarching FRESH study. All authors informed the data analysis, assisted in the interpretation of results, critically revised the manuscript, and approved the final version.

\section{References}

1. Gittelsohn J, Lee-Kwan SH, Batorsky B. Community-based interventions in prepared-food sources: a systematic review. Prev Chronic Dis [Internet]. 2013 Oct 31 [cited 2016 Nov 4];10: 130073. Available from: http://dx.doi .org/10.5888/pcd10.130073
2. Gittelsohn J, Rowan M, Gadhoke P. Interventions in small food stores to change the food environment, improve diet, and reduce risk of chronic disease. Prev Chronic Dis [Internet]. 2012 [cited 2016 Nov 4];9:110015. Available from: http://dx.doi.org/10 $.5888 /$ pcd9. 110015

3. Glanz K, Bader MDM, Iyer S. Retail grocery store marketing strategies and obesity: an integrative review. Am J Prev Med. 2012;42(5):503-12.

4. Cameron AJ, Charlton E, Ngan WW, Sacks G. A systematic review of the effectiveness of supermarket-based interventions involving product, promotion, or place on the healthiness of consumer purchases. Current Nutrition Reports. 2016;5(3):129-38.

5. Glanz K, Sallis JF, Saelens BE, Frank LD. Healthy nutrition environments: concepts and measures. Am J Health Promot. 2005;19(5):330-3.

6. Ni Mhurchu C, Vandevijvere S, Waterlander W, et al. Monitoring the availability of healthy and unhealthy foods and non-alcoholic beverages in community and consumer retail food environments globally. Obes Rev. 2013; 14(Suppl 1):108-19.

7. Statistics Canada. Average household food expenditure, by province (Canada) [Internet]. Ottawa (ON): Statistics Canada; [modified 2017 Jan 27; cited 2014 Dec 05]. Available from: http:// www.statcan.gc.ca/tables-tableaux /sum-som/101/cst01/famil132a-eng .htm.

8. Brimblecombe J, Liddle R, O’Dea K. Use of point-of-sale data to assess food and nutrient quality in remote stores. Public Health Nutr. 2013;16(7):1159-67.

9. Foster GD, Karpyn A, Wojtanowski AC, et al. Placement and promotion strategies to increase sales of healthier products in supermarkets in low-income, ethnically diverse neighborhoods: a randomized controlled trial. Am J Clin Nutr. 2014;99(6):1359-68.

10. Fuller D, Engler-Stringer R, Muhajarine $\mathrm{N}$. Examining food purchasing patterns from sales data at a full-service grocery store intervention in a former food desert. Prev Med Rep. 2015;2:164-9.
11. Ni Mhurchu C, Vandevijvere $\mathrm{S}$, Waterlander W, et al. Monitoring the availability of healthy and unhealthy foods and non-alcoholic beverages in community and consumer retail food environments globally. Obes Rev. 2013;14(S1):108-19.

12. Song HJ, Gittelsohn J, Kim M, Suratkar S, Sharma S, Anliker J. A corner store intervention in a low-income urban community is associated with increased availability and sales of some healthy foods. Public Health Nutr. 2009;12(11):2060-7.

13. Budd N, Cuccia A, Jeffries JK, et al. B'more healthy: retail rewards design of a multi-level communications and pricing intervention to improve the food environment in Baltimore City. BMC Public Health [Internet]. 2015 Mar 24 [cited 2017 May 5];15:283. doi: 10.1186/s12889 -015-1616-6.

14. Lent MR, Vander Veur SS, McCoy TA, et al. A randomized controlled study of a healthy corner store initiative on the purchases of urban, low-income youth. Obesity (Silver Spring). 2014; 22(12):2494-500.

15. Ayala GX, Baquero B, Pickrel JL, et al. A store-based intervention to increase fruit and vegetable consumption: The El Valor De Nuestra Salud cluster randomized controlled trial. Contemp Clin Trials. 2015;42:228-38.

16. Brimblecombe $J$, Ferguson $M$, Liberato SC, et al. Stores Healthy Options Project in Remote Indigenous Communities (SHOP@RIC): a protocol of a randomised trial promoting healthy food and beverage purchases through price discounts and in-store nutrition education. BMC Public Health [Internet]. 2013 Aug 12 [cited 2016 Nov 6];13:744. doi: 10.1186/1471 -2458-13-744.

17. Magnus A, Moodie ML, Ferguson M, Cobiac LJ, Liberato SC, Brimblecombe J. The economic feasibility of price discounts to improve diet in Australian Aboriginal remote communities. Aust N Z J Public Health. 2016; 40(Suppl 1):S36-S41.

18. Holmes AS, Estabrooks PA, Davis GC, Serrano EL. Effect of a grocery store intervention on sales of nutritious foods to youth and their families. J Acad Nutr Diet. 2012;112(6):897-901. 
19. Minaker LM, Olstad DL, MacKenzie $G$, et al. An evaluation of the impact of a restrictive retail food environment intervention in a rural community pharmacy setting. BMC Public Health [Internet]. 2016 Dec [cited 2017 May 5];16:586. Available from: http://dx.doi.org/10.1186/s12889-016 $-3281-9$

20. Gittelsohn J, Laska MN, Karpyn A, Klingler K, Ayala GX. Lessons learned from small store programs to increase healthy food access. Am J Health Behav. 2014;38(2):307-15.

21. Gardiner B, Blake M, Harris R, et al. Can small stores have a big impact? A qualitative evaluation of a store fruit and vegetable initiative. Health Promot J Australia. 2013;24(3):192-8.

22. Mah CL, Cook B, Rideout K, Minaker LM. Policy options for healthier retail food environments in city-regions. Can J Public Health. 2016;107(Suppl 1):eS64-eS67.

23. City of Toronto. City of Toronto ward profiles: 2011 census, Ward 43 Scarborough East [Internet]. Toronto (ON): City of Toronto; 2014 [cited 2016 Nov 28]. Available from: http:// www 1.toronto.ca/City \% 200f \% 20 Toronto/City \% 20Planning/Wards /Files /pdf/W / Ward \% $2043 \% 20$ Profile\%202011.pdf

24. City of Toronto. City of Toronto ward profiles: 2011 National Household Survey, Ward 43 -Scarborough East [Internet]. Toronto (ON): City of Toronto; 2014 [cited 2016 Nov 28]. Available from: http://www1.toronto .ca/City \% 200f\% 20Toronto/City \% 20 Planning/Wards/Files/pdf/W/Ward $\% 2043 \%$ 20NHS \% 20Profile \% 202011 .pdf

25. Dachner N, Ricciuto L, Kirkpatrick SI, Tarasuk V. Food purchasing and food insecurity among low-income families in Toronto. Can J Diet Pract Res. 2010;71(3):e50-e56.

26. Vozoris N, Davis B, Tarasuk V. The affordability of a nutritious diet for households on welfare in Toronto. Can J Public Health. 2002;93(1):36-40.

27. Mah CL, Hasdell R, Soo S, Cook BE, DeMaio A, Minaker LM. Entrepreneurialism and population health interventions in the retail food environment. Health Promotion International. Forthcoming 2017.
28. Mah CL, Minaker LM, Jameson K, et al. An introduction to the healthy corner store intervention model in Canada. Can J Public Health. Forthcoming 2017.

29. Webber CB, Sobal J, Dollahite JS. Shopping for fruits and vegetables. Food and retail qualities of importance to low-income households at the grocery store. Appetite. 2010; 54(2):297-303.

30. Dunaway LF, Mundorf AR, Rose D. Fresh fruit and vegetable profitability: insights from a corner store intervention in New Orleans, Louisiana. J Hunger Environ Nutr. 2016:1-10.

31. Kraak VI. Public health and food and beverage industry engagement: a tool to assess partnership opportunities and challenges. Toronto (ON): The Healthy People and Communities Steering Committee's Multi-Sectoral Partnerships Task Group; 2014. 19 p. 